\title{
Fatal Accidents During Marine Transport of Wood Pellets Due to Off-gassing - Experiences from Denmark
}

\section{Hedlund, Frank Huess; Jarleivson Hilduberg, Øssur}

Published in:

Biomass Volume Estimation and Valorization for Energy

Link to article, DOI:

$10.5772 / 66334$.

Publication date:

2016

Document Version

Publisher's PDF, also known as Version of record

Link back to DTU Orbit

Citation (APA):

Hedlund, F. H., \& Jarleivson Hilduberg, Ø. (2016). Fatal Accidents During Marine Transport of Wood Pellets Due to Off-gassing - Experiences from Denmark. In J. S. Tumuluru (Ed.), Biomass Volume Estimation and Valorization for Energy (pp. 73-97). InTechOpen. https://doi.org/10.5772/66334.

\section{General rights}

Copyright and moral rights for the publications made accessible in the public portal are retained by the authors and/or other copyright owners and it is a condition of accessing publications that users recognise and abide by the legal requirements associated with these rights.

- Users may download and print one copy of any publication from the public portal for the purpose of private study or research.

- You may not further distribute the material or use it for any profit-making activity or commercial gain

- You may freely distribute the URL identifying the publication in the public portal 


\section{World's largest Science, Technology \& Medicine Open Access book publisher}
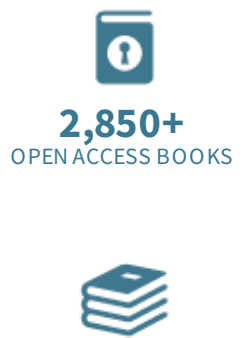

BOOKS

DELIVERED TO 151 COUNTRIES

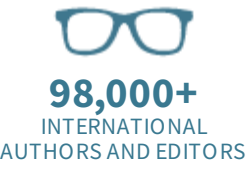

AUTHORS AMONG

TOP $1 \%$

MOST CITED SCIENTIST
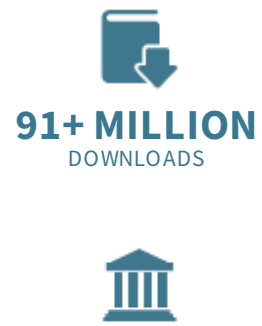

$12.2 \%$

AUTHORS AND EDITORS FROM TOP 500 UNIVERSITIES

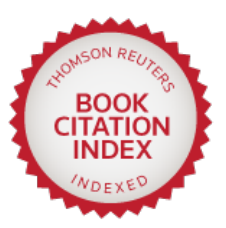

Selection of our books indexed in the Book Citation Index in Web of Science ${ }^{\mathrm{TM}}$ Core Collection (BKCl)

Chapter from the book Biomass Volume Estimation and Valorization for Energy Downloaded from: http://www.intechopen.com/books/biomass-volume-estimationand-valorization-for-energy 
Chapter 4

\title{
Fatal Accidents During Marine Transport of Wood Pellets Due to Off-Gassing: Experiences from Denmark
}

\author{
Frank Huess Hedlund and \\ Øssur Jarleivson Hilduberg
}

Additional information is available at the end of the chapter

http://dx.doi.org/10.5772/66334

\begin{abstract}
The atmosphere in unventilated wood pellet storage confinements, such as the cargo hold of marine vessels transporting pellets in solid bulk, can be severely oxygen deficient and contain deadly concentrations of harmful gasses, of which the most feared is the poisonous and odour-less carbon monoxide. The hazard has been known for over a decade and has been responsible for many accidents. We examine three fatal accidents on marine vessels in or near Danish waters and argue that they share strikingly similar aetiologies, if not repetitive patterns. It is generally recognized that accidents should be thoroughly investigated and lessons learned shared widely in order to minimize the number of times the same lessons have to be learned. The three Danish cases suggest that this learning process is deeply troubled for the solid biomass segment. The International Maritime Organization IMO/SOLAS has recently revised its guidance on entering enclosed spaces aboard ships in response to the ongoing problem of confined space incidents. We argue that the interpretation of the concept of an "enclosed space" is of utmost importance because accidents take place in rooms that are not considered enclosed by the crew.
\end{abstract}

Keywords: wood pellets, off-gassing, confined space, accident investigation

\section{Introduction}

This paper pays homage to what may be man's oldest accident prevention strategy: Learning from own-and better, other people's - past accidents and misfortune. In its modern form, the key characteristics of this strategy are that past mishaps shall be recorded and analysed to extract lessons learned which in turn shall be disseminated through broad feedback loops in order to prevent future similar, and not just identical, accidents. 
Paraphrasing Petroski [1], the profession of accident prevention professionals is Janus-faced, looking always both backwards and forwards. The history of past accidents offers a repository of knowledge gained from painful experience. If heeded, the past thus provides caveats and lessons for future safe operations. If shunned, it will still haunt the future, always lurking in the shadows everyday work.

Having paid the price of an accident, we should use the opportunity to learn from it. The benefits of such learning are obvious - to avoid repetition, and to share the lessons learned in order to minimize the number of times the same lessons have to be learned. What is not so obvious, however, is how to make this seemingly simple and straightforward idea work in practice [2]. This challenge is reflected in common aphorisms, such as Santanyana's: Those who cannot remember the past are condemned to repeat it.

This paper examines three fatal accidents on marine vessels transporting sustainable, environmentally friendly and carbon-neutral wood pellets in bulk, in or near Danish waters, and argue that they share strikingly similar aetiologies, if not repetitive patterns-offering support to Sanatnyana's dismal adage. The paper examines some of the barriers that impede the capacity to learn from accidents on marine vessels in this particular segment.

\section{Wood pellets in bulk}

\subsection{Solid biomass fuel in Danish thermal power plants}

To reduce global carbon dioxide emissions, Denmark has converted many coal-fired thermal power plants to burn green and sustainable solid biomass. Solid biomass refers to non-fossilized carbon-based solid materials derived from plants, typically wood, but also straw, and certain energy crops grown primarily for the purpose of fuel utilization. Because Denmark's own woodlands are limited and covered by environmental protection policies, the domestic production of solid biomass is insignificant. Hence, essentially all biomass is imported, mostly from loggings in the Baltic countries and Russia, but also from North America and Africa [3].

Thermal power plants consume very large amounts of fuel; a single block can easily burn half a million metric ton per year. In order for the logistics chain to handle such quantities in an efficient manner, the irregularly sized and bulky biomass is processed into uniformly sized pellets, typically about $8 \mathrm{~mm}$ in diameter and 20-25-mm length.

In the production process, the wood is dried, milled to a fine powder and compacted in a pellet press that often employ die ring press and compression roller technology. The pellets are shipped in bulk in marine vessels to their final destination.

\subsection{Wood pellet fire and explosion risks}

The fire and explosion hazard profile of biomass pellets is much different from that of coal [3]. Pellets inevitably generate fine dust when handled in the logistics chain, e.g. in screw 
conveyors, band conveyors, cup elevators and when dumped into storage areas or hoppers. If made airborne and ignited, the wood dust is capable of producing severe dust explosions.

In addition, this dust is prone to ignition, e.g. from overheated electric motors or conveyor bearings, or from mechanical friction heat between conveyer belts and accumulated pellets, fines and/or dust. Small pieces of smouldering material are difficult to detect and they may migrate in the band conveyor systems and start smouldering fires in the storage areas which may develop into massive storage fires. Smouldering fires are furthermore notorious for their capacity to generate flammable pyrolysis gasses that travel and accumulate, leading to flash fires or explosion hazards elsewhere in the system [4].

\subsection{Wood pellet chemical off-gassing risks}

The milling process, the compaction and extreme shear forces in the pellet press, cause plant cell walls to rupture. This exposes cell cytoplasm and chemically reactive compounds such as resins, oils and fatty acids to air making them available to chemical oxidation and other reactions. As a result, freshly produced wood pellets are probably best thought of as a chemically active material.

The chemically active pellets may emit a range of gasses such as carbon monoxide, carbon dioxide, methane and volatile organic compounds (VOCs) that can accumulate in storage confinements and reach dangerous levels [5]. The release of the highly poisonous and odourless carbon monoxide is of particular concern. In addition, the chemical reactions may deplete the atmosphere in storage confinements of the oxygen required to sustain life. The topic has been investigated in several recent publications, e.g. [6, 7] but the exact nature of the chemical processes at play do still not appear to be well-understood.

Chemical oxidation may also explain why wood pellets can self-ignite. Heat loss is largely a surface-based phenomenon and because of the low surface-to-volume ratio of a large pile, any process that generates heat will slowly increase the temperature inside the pile. Pockets may form where the temperature of the contents can rise to the temperature necessary to produce spontaneous ignition. This produces an oxygen deficient smouldering fire deep inside the pile and the associated problems with flammable pyrolysis gasses that travel and accumulate, leading to flash fires or explosion hazards elsewhere in the system.

It is true that some biomass feedstocks species rich in resins are desirable in the pellet production process. The mechanical stability of pellets is an important property as this limits the amount of dust generated when they are handled in the logistics chain. Pellet stability is enhanced if the mill feed composition includes some biomass species rich in resins, e.g. pine wood, which can act as a natural binder system. Naturally occurring oils and resins can have other beneficial properties during production, for instance acting as lubricants in the pellet press. It will probably be difficult to reduce the problem with chemical reactivity of wood pellets through substitution of resin-rich species in the feedstock unless, of course, non-bio but safer additives are tolerated by pellet consumers.

What is clear though is that the massive increase in wood pellets consumption entails novel risks - wood pellets have a much different hazard profile than fossil fuel cargoes. 


\section{Case 1-Fatal accident on AMIRANTE, 2009}

\subsection{AMIRANTE}

The ship AMIRANTE (IMO 7425334) was a general cargo ship enabling it to carry a variety of bulk and mixed cargos. It was built in 1978/1982 and had a gross tonnage of 4083 and a length of $82 \mathrm{~m}$. The vessel was classed by DNV.

At the time of the accident, the vessel had a crew of eight, seven from the Russian Federation and one from Belarus. The flag State was St. Vincent \& The Grenadines. AMIRANTE was mainly in a coastal trade in northern Europe and the Mediterranean.

\subsection{Sources}

Information on this accident is based on records from the Danish police [8] obtained through the Danish equivalent of a Freedom of Information Act unless otherwise noted.

\subsection{The accident}

On 15 July 2009 at 0300 (all times are local time), AMIRANTE left the port of Riga, Latvia, after having loaded a cargo of $2600 \mathrm{t}$ of wood pellets in bulk. The port of destination was Copenhagen, Denmark, were the cargo was to be unloaded at the Amagerværket power plant owned by Wattenfall, which had recently converted one of its coal fired blocks from coal to solid biomass. The shipper was Granul Invest in Tallinn, Estonia and the operator was Alga Chartering in Copenhagen.

On the afternoon 15 July, during the passage of the Baltic Sea, four of the vessel's crew, three able seamen and the motorman, worked on the deck readying new mooring ropes on the forward part of the ship.

Shortly after 1800, the master was alerted by the ship's cook that one of the able seamen and the motorman had not shown up for dinner and their whereabouts were unknown. A search was initiated and at 1835, a crew member spotted the missing crew members lying lifeless at the bottom of the stairwell to the forepeak compartment. The crew member did not attempt to reach them fearing for his own safety.

The forepeak is a wedge-shaped stowage room at the bow of the ship, about $5 \mathrm{~m}$ deep, and a width ranging from 5 to $1.5 \mathrm{~m}$. The room is reached from the deck through a stairwell climbing a narrow 18-m long fixed vertical steel ladder. The forepeak was used for stowing, e.g. paint containers, floor brushes, buckets, surplus wooden planks and mooring ropes.

The master rushed to the forepeak and climbed down the steel ladder. Halfway down he began to experience laboured breathing. Upon reaching the forepeak floor his breathing had become so laboured that he realized the atmosphere might be dangerous. The motorman was lying about $1 \mathrm{~m}$ from the ladder and the able seaman was lying just at the foot of the ladder, as if he had attempted to climb it, still wearing work gloves. Froth could be seen from the 
corner of the mouth of both men. The master briefly tried to awaken them and then hurried up the ladder to the deck. The vessel was about $16 \mathrm{~km}$ north of Bornholm, a Danish island in the Baltic Sea about midway between Sweden and Poland. At 1845, the master radioed the Danish authorities requesting immediate medical assistance.

The crew worked frantically to extract the two men from the forepeak compartment. They switched the room's mechanical ventilation on and crew members climbed down the ladder to tie a rope around the chest of the victims. Hoisting the victims through the narrow stairwell proved difficult. When a doctor arrived by helicopter from the Danish Admiral Fleet, at 1945, one victim has been extracted and there was a work frenzy to hoist the other. The doctor could soon declare both men dead as they presented with livor mortis and beginning rigor mortis. The doctor estimated that death had occurred 2-3 h earlier.

\subsection{The investigation}

The vessel was redirected to the port of Rønne at Bornholm by Danish Admiral Fleet, where it arrived at 2300. The police was waiting at the quay and began a standard crime scene procedure, securing evidence and interviewing the crew. The forepeak was inspected by the fire and rescue services done full breathing protection at about 0100. At the time of the inspection, the compartment's mechanical ventilation had been switched off for about 40 min upon request. Oxygen levels were normal, $\mathrm{CO}$ levels were $100 \mathrm{ppm}$. The inspection team noticed a pair of glasses which had been placed on some stowed construction timber and an unopened packet of cigarettes lying on the floor.

A door in the forepeak compartment allowed access to the front cargo hold. The door had three closing hinges but only two were engaged. It was speculated that gasses might travel from the cargo hold to the forepeak through a crevice in the door opening where the third hinge was not engaged (Figure 1).

The deceased presented no signs of violence or trauma and there was no other evidence to suggest criminal actions, e.g. if they should have been pushed while standing in the door opening on the deck and then fallen the $18 \mathrm{~m}$ down the forepeak stairwell. There was briefly some speculation if red stains on the floor of the forepeak were bloodstains but they turned out to be red paint. Follow-up interviews with the master and other crew members were carried out in the afternoon to resolve some inconsistencies in reported times and observations, this time with the assistance of a certified interpreter. Only the master spoke some English, and he had acted as interpreter during the first interviews.

A sample of the wood pellets was sent for chemical analysis which found $150 \mathrm{ppm}$ CO in the headspace of the specimen jar. The actual concentration is likely much higher, however, as $150 \mathrm{ppm}$ simply appears to be the upper range of the measuring instrument. An autopsy confirmed death by $\mathrm{CO}$ poisoning, $\mathrm{COHb}$ blood saturation levels were measured at $52 \%$ (the motorman) and 60\% (the able seaman). Tests for cyanide (blood) and alcohol (lacrimal fluid) were negative. 


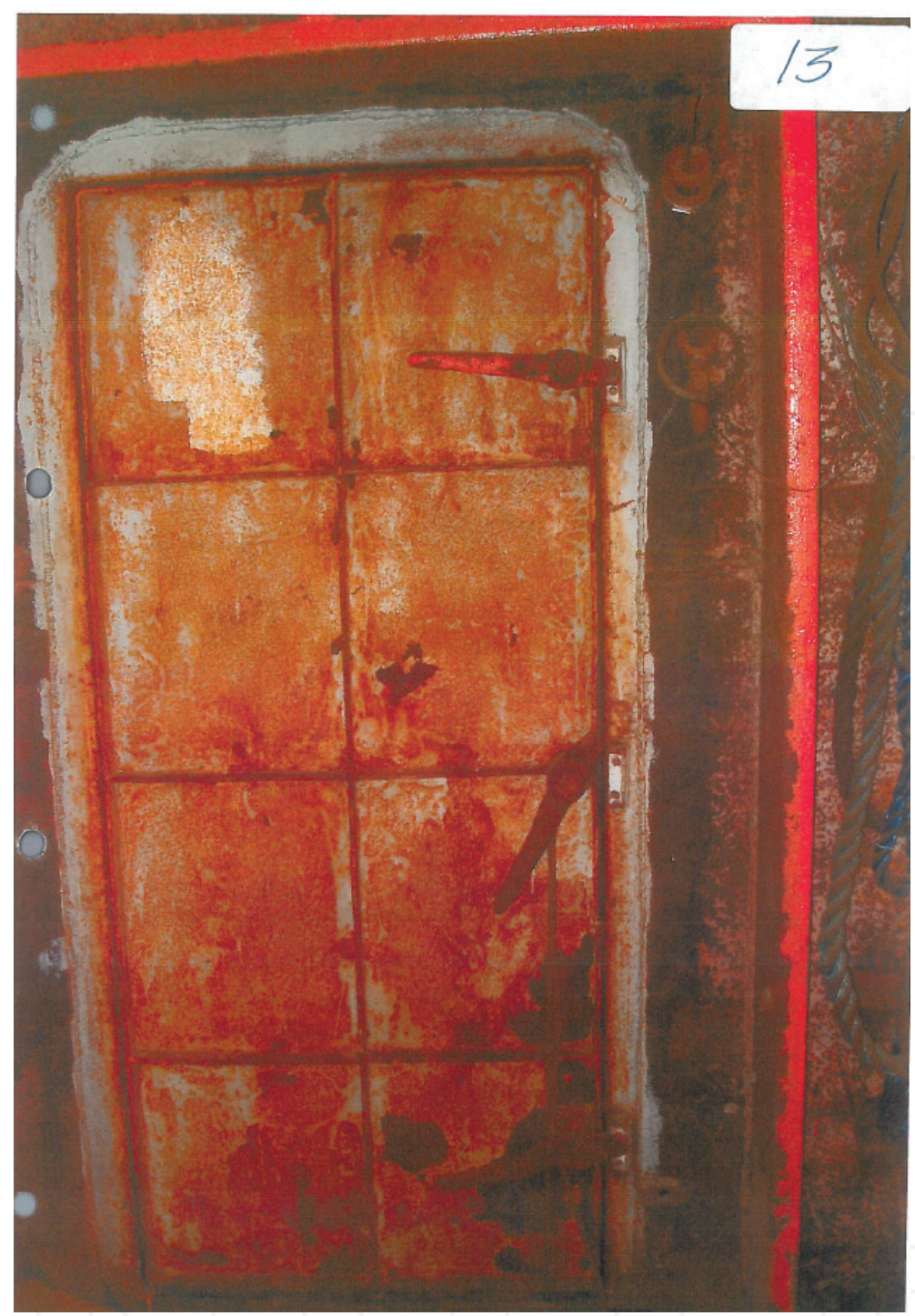

Figure 1. The door in the forepeak compartment, which led the front cargo hold. The door had three closing hinges but only two were engaged. Gasses travelled from the cargo hold to the forepeak through a crevice where the third hinge was not engaged. (AMIRANTE). Source: Police photo file \#13 [8].

The crew was at pains to explain why the two seamen would go down the forepeak. They had no business down there whatsoever. It was suggested that they might want to check if there was sufficient room for stowage of the old mooring ropes.

The two deceased were experienced seamen. The motorman was born in 1981 in Russia, the able seaman in 1971 in Belarus. Records showed that both seamen had duly complied 
with regulations concerning rest and work time. Both seamen had received the proper safety instruction for working in enclosed rooms in 2008 (July 8 and April 20, respectively) and they were not newcomers to the ship. Police records state that they should have known that full breathing protection was required before entering a compartment such as the forepeak. In the absence of evidence of the contrary, the police ruled the two deaths an unfortunate workplace accident and the crime scene investigation was closed.

\subsection{Reflections}

The direct cause of the accident is probably simple and understandable. Working new and bulky mooring ropes, often weighing several $100 \mathrm{~kg}$, is a laborious and tedious task. According to the weather data from Rønne airport, the afternoon weather conditions were mostly cloudy, temperature $17-19^{\circ} \mathrm{C}$, light winds about $3 \mathrm{~m} / \mathrm{s}$ and occasional rain showers and light rains. While such ambient weather conditions definitely are tolerable to seasoned seamen, it is easy to imagine that the nearby forepeak might offer a convenient refuge for a clandestine cigarette break, in particular during a rain shower.

Important questions aimed at understanding why the accident happened were never raised, simply because they were out scope of a judicial police investigation. Were the crew aware of hazardous properties of the cargo? Was the forepeak considered to be a compartment with properties similar to those of enclosed cargo spaces? The starkest circumstantial evidence may be that the two seamen chose to enter the forepeak without switching on the mechanical ventilation. In all likelihood, they were clueless about the danger-otherwise, they would not have entered. Were the rest of the crew and in particular the master aware of the hazard? Although it is pure conjecture, the answer is probably negative. In the police interrogation reports, none of the crew mentioned the ability of wood pellets to generate carbon monoxide. The closest mention was the master stating that he suspected something was "wrong" with this particular cargo, because it had a "funny smell" unlike any of the 15 earlier occasions where AMIRANTE had carried wood pellets.

Was information about the hazardous nature of the cargo available to the crew? The question too was never raised and although the answer is uncertain it is probably negative. The manifest of cargo simply stated: "Wood Pellets in bulk-Cargo Status C-European Community Cargo" and the "Dangerous" field on the manifest form was left blank.

The criminal investigation was satisfied that the two seamen had received the proper safety instruction for working in enclosed rooms and concluded that they should have known that full breathing protection was required before entering a compartment such as the forepeak. The question was never raised, however, if the seamen, or the rest of crew for that matter, would consider the forepeak "an enclosed room". The police interrogation reports state that the practice on board the vessel was to lock open the door on the deck that provided access to the stairwell to the forepeak. The door was only closed during bad weather. The reason for this practice is unexplained. But in the absence of specific precautionary instructions or warnings, the crew may well have assumed that a room with a door locked open is not "enclosed". 


\subsection{Information sharing and learning}

The local news media at Bornholm briefly covered the event, reporting that a coaster with two dead sailors had arrived at the port of Rønne. At the time of media reporting the cause had not yet been determined, and the media speculated that $\mathrm{CO}$ poisoning or oxygen deficiency in an enclosed room might be responsible for a workplace accident. The vessel's cargo was correctly identified as wood pellets, but there is nothing in the media coverage to suggest that there might be a causal link between the type of cargo and the presence of toxic gasses. For an accident prevention professional, the media coverage is worthless.

Because the police opened the case as a crime scene investigation, the case was technically registered as a criminal case. Criminal cases are kept confidential in order to protect the privacy of the individuals concerned. To date, very little information, if any, relevant to accident prevention professionals is available in open sources. The source material for this paper could only be obtained through persistent requests and the Danish equivalent of a Freedom of Information Act.

It is true that there is sporadic and passing mention of the AMIRANTE accident in the wood pellet literature, e.g. $[9,10]$ but descriptions are hazy and basic facts are corrupted. This is also true for the papers produced by authors in Denmark. For example [11] states that the seamen entered the cargo hold, which they did not, and [12] states that they died from asphyxia, which is also incorrect.

Because proper sharing of correct information about an accident is a basic precondition for learning, we conclude that learning processes were derailed at a very early stage. Therefore, it may be expected that repeat accidents will take place. As we will argue shortly, this is precisely what happened. Lamentably, the broader accident history reveals that the AMIRANTE accident was no first, but only one in a string of previous similar accidents with similar aetiologies.

\section{Case 2-Fatal accident at "LADY IRINA", 2014}

\subsection{LADY IRINA}

The ship LADY IRINA (IMO 9137038) was a general cargo ship with capacity to carry containers enabling it to carry a variety of bulk and general cargo. LADY IRINA was built in 1997 with a gross tonnage of 3323 and a length of $88 \mathrm{~m}$. The vessel was classed by Lloyd's Register. At the time of the accident, the vessel had a crew of seven. The flag state was The Netherlands.

\subsection{Sources}

Information on this accident is based on a report from the Dutch Safety Board [13] unless otherwise noted.

\subsection{The accident}

On 5 July 2014, LADY IRINA departed from the Port of Arkhangelsk, Russia, with a cargo of wood pellets in bulk which was to be unloaded in Kolding, Denmark. Arkhangelsk is LADY 
IRINA's permanent loading port for this type of cargo, and it has a dozen discharge ports in Europe, of which Kolding is one.

On the evening of 13 July 2014, the crew prepared for LADY IRINA's arrival in the Port of Kolding. At about 1900, the chief engineer met with the chief officer and decided to drain the anchor chain locker compartment before LADY IRINA expected arrival at about $2400 \mathrm{~h}$. The anchor chain locker is located in the forward part of the ship. Access to the anchor chain locker is from the deck, entering the forecastle compartment, opening a door and climbing a vertical steel ladder in a stairwell to the bow thruster room, located directly beneath the forecastle room.

The forecastle compartment holds maintenance and safety equipment and other frequently used items such as tools, paint and brushes. The door to the forecastle room is therefore normally open throughout the day and only closed at the end of work, typically at about 1700, to secure the watertight integrity of the ship while the crew were off duty.

On 13 July, sometime after 1900, the chief engineer went to the engine room to start the pump draining the anchor chain locker and then went to the bow thruster room, probably to check if the draining operation was complete. The door to the forecastle had been closed since end of work Saturday, i.e. for at least $26 \mathrm{~h}$.

At 2145, the chief officer went looking for the chief engineer. The door to the forecastle room was open and he found the chief engineer lifeless on the floor of the deck lower, on the floor of the bow thruster room. He examined the chief engineer and found that he was not breathing and had no heartbeat.

The chief officer rushed to the bridge to alert the master, who had the watch, and to summon assistance. The second mate, who happened to be on the bridge was ordered to go to the accident site with a stretcher. The master immediately decided to divert to the nearby port of Fredericia (Denmark), only 4 nautical miles away, and requested emergency assistance to be ready at the quay.

The chief officer went to the crew accommodation to alert the rest of the crew and directed them to the bow thruster room. Probably at about 2215, all crew members except the master were involved in the rescue operation in the bow thruster room. They first worked to resuscitate the chief engineer and then attempted to evacuate him through the stairwell on the stretcher, which proved unsuccessful as he was a heavily built man. The rescue involved six crew members: the first and second mates, the apprentice engineer, the cook and two seamen. They did not use the breathing apparatus that they had taken with them because they thought that the chief engineer had fallen from the ladder and that air quality was not a problem.

Around 2245, the vessel arrived in the Port of Frederica and the apprentice engineer and a seaman left the bow thruster room to assist with berthing the vessel. The bow thruster was required for berthing and had to be operated from the engine room. The second mate also left the room to collect a neck brace because the crew still thought that the chief engineer had fallen from the ladder, and an oxygen kit because the chief engineer was not breathing. 
Upon returning to the forecastle room, a few minutes later, the second mate saw the chief officer unconscious, a crew member trying to carry him away and another crew member walking around as if drunk. The second mate climbed down ladder to the bow thruster room, placed a breathing apparatus over the mouth of the chief officer and urged the two other crew members to leave the room. He then left the bow thruster room and forecastle himself because he did not feel well. Before leaving the forecastle, he opened the medical oxygen kit and lowered it down the bow thruster room with a rope, in order to generate extra oxygen there.

The vessel berthed at 2250 and the local fire and rescue services evacuated the chief engineer and the chief officer from the bow thruster room. The other two crew members had managed to climb the ladder and get outside by themselves but were much weakened. The chief officer was given oxygen and regained consciousness on deck.

The chief officer and the two seamen were admitted to hospital and were diagnosed with carbon monoxide poisoning. The chief engineer had died from carbon monoxide poisoning. Danish news media [14] report that four, not three, seamen were admitted to hospital and two of them were treated in a hyperbaric oxygen therapy chamber. All crew appear to be of Russian nationality.

The local fire and rescue services ventilated the forecastle and bow thruster room with electrical ventilators for $1 \frac{1}{2} \mathrm{~h}$ and then took $\mathrm{CO}$ measurements. $\mathrm{CO}$ levels in the forecastle were measured at $80 \mathrm{ppm}$, bow thruster room at $20 \mathrm{ppm}$. After having the forecastle and bow thruster rooms closed for $36 \mathrm{~h}$, the measurements were 690 and $555 \mathrm{ppm}$, respectively. The LADY IRINA is equipped with a fixed $\mathrm{CO}_{2}$ system, which can inject carbon dioxide in the cargo hold for firefighting purposes. $\mathrm{CO}$ concentrations in the neighbouring carbon dioxide storage room, which had not been ventilated, were in excess of 2000 ppm, the upper limit of the measuring device.

\subsection{The investigation}

The investigation by the Dutch Safety Board [13] concluded that carbon monoxide generated by the wood pellets in the unventilated cargo hold could potentially have reached the bow area in several ways, e.g. via piping or ventilations ducts:

The $\mathrm{CO}_{2}$ room, forecastle and bow thruster room are adjacent to each other and gasses might travel from one room to another through a number of connecting conduits. The shipping company contracted the classification society to investigate how carbon monoxide could have travelled from the cargo hold to the bow area. The investigation identified a minor gap in a section of the rim of an inspection cover on a ventilation duct that runs from the cargo hold through the forecastle as the most likely route (Figure 2).

The atmosphere in the bow area had been identified as potentially unsafe and warning signs on the forecastle access door stated: "DANGER. Low Oxygen Level". The bow area had no mechanical ventilation. In principle, according the rulebook, the bow area should probably be considered a confined space. At LADY IRINA, however, the daily work practice had evolved and adapted to the need to enter the room on a routinely and daily basis. The crew simply opened the door for 15-20 min to allow natural ventilation before entering and they would normally leave the door open. 


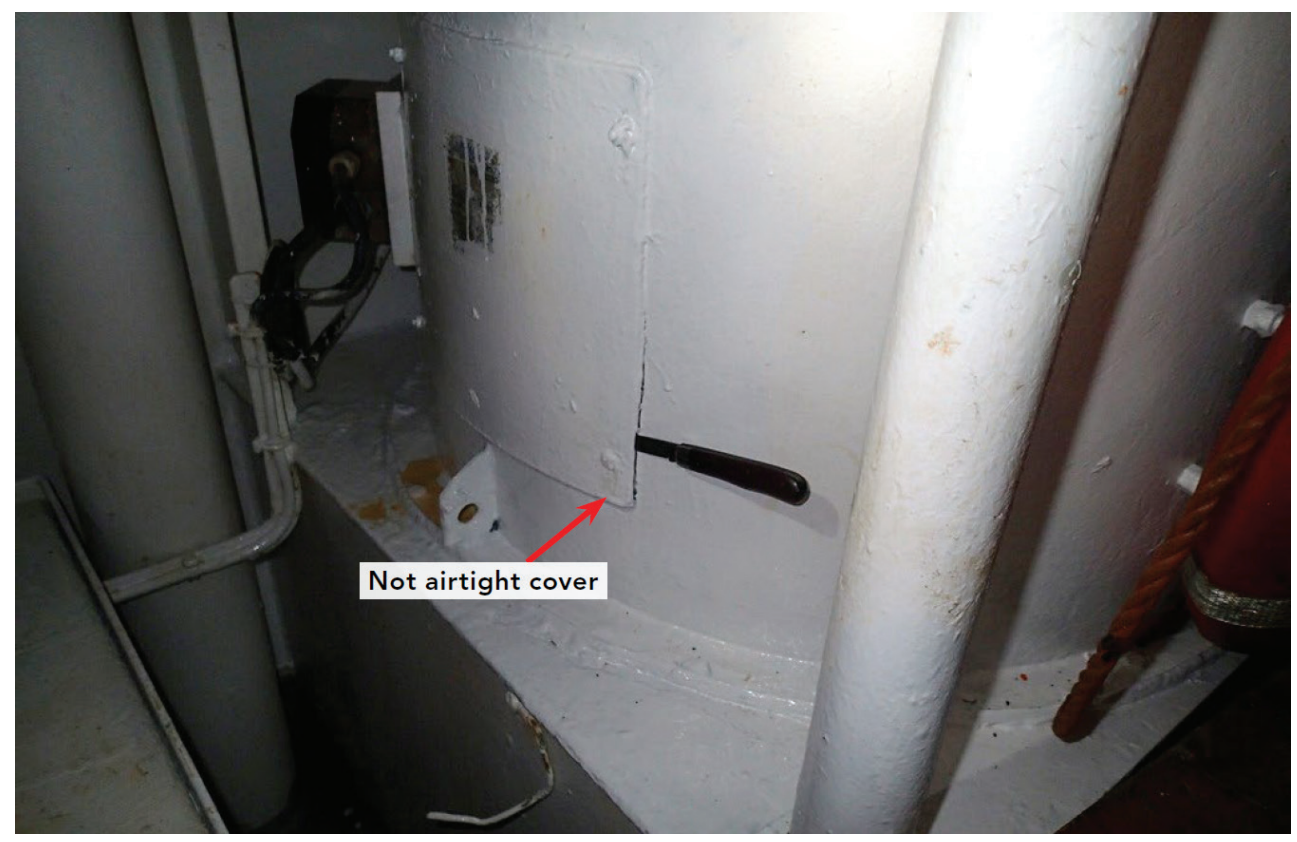

Figure 2. The inspection hatch on a ventilation duct that ran from the cargo hold through the forecastle. A minor gap in a section of the rim (knife blade inserted) allowed gasses to travel from the cargo hold to the bow area. (LADY IRINA). Source: [13].

In response to the fatal accident, the shipping company acquired multi-gas meters and introduced a new work procedure mandating that the person making "First Entry" must carry an operational multi-gas meter. New warning placards with the instruction "ATTENTION-No first entry without use of multi-gas meter" were been put up on access doors.

The investigation report states that: "The [Dutch Safety] Board is of the opinion that, in the light of this accident, it is good that the shipping company examines the working method that was common in practice. However, the new working method desires focus on definition and crew discipline during use. The working method should also be evaluated and improved, where necessary" [13].

\subsection{Reflections}

The most striking feature of this accident is probably that the entire crew, except the master on the bridge, climbed down the ladder to the bow thruster room where dangerous levels of carbon monoxide were present and stayed there for more than $30 \mathrm{~min}$, completely oblivious of the danger. It is easy to imagine that under just marginally different circumstances, the entire crew would have succumbed to the poisonous gasses down there, which in turn would have hampered the master's ability to berth the vessel and hence delayed the arrival of the rescue services. It can safely be stated that the death toll could have been higher. 
The Dutch investigation observes that the relevant International Maritime Solid Bulk Cargoes (IMSBC) Code for wood pellets at the time of the accident stated that: "all crew members must carry an oxygen and carbon dioxide meter and switch this on when they enter the cargo hold or adjacent confined spaces". We observe that there is only superficial and passing mention of carbon monoxide in the Code. We also remark that an atmosphere with deadly levels of CO may present with normal readings for oxygen and $\mathrm{CO}_{2}$.

Was information about the hazardous nature of the cargo available in a form that made the crew aware of the risk? The investigation does not clearly address this issue. The investigation simply states that the crew "was informed of the risks of this cargo" and that they "knew that the hold should not be entered". Furthermore that "each new crew member had received safety instructions" which comprised "confined spaces and ventilation of holds in connection with possible lack of oxygen and other dangerous substances that emerge as a consequence of cargo. Also during the safety committee meetings attention was paid to entering confined spaces".

We conclude that the answer probably is negative: information was not available to the crew. In any case, their actions demonstrate that they were clueless of breathing hazards of any kind, be it oxygen depletion, carbon dioxide, carbon monoxide, etc.

For a safety professional working with industrial accident prevention (onshore), it is unusual that rooms routinely entered on a daily basis are, first, identified and labelled as having a potentially unsafe atmosphere, and second, do not have mechanical ventilation. The absence of mechanical ventilation would appear to be a weakness in design, which ought to be eliminated in future designs and retrofitted in existing designs wherever possible. Mechanical ventilation is a risk prevention measure, whereas testing before entry is a risk control measure, merely to confirm that the preventive measures are successful. It is remarkable that a relatively recently built ship (1997) has no mechanical ventilation where dangerous gasses potentially may be present.

\subsection{Information sharing and learning?}

The accident has been investigated and the findings exhaustively communicated by the Dutch Safety Board [13]. The coverage in Danish new media correctly identifies the generation of CO from wood pellets as the culprit and has no factual errors [14]. A Maritime Merchant Periodical with international coverage [15] carried an article that summarized the findings of Dutch Safety Board's accident report, highlighting that other crew members could have been killed in the rescue attempt. The article is without factual errors. The information provided is sufficiently detailed to permit safety professionals elsewhere to prevent recurrence.

The basic preconditions for learning: broad sharing of relevant and factually correct information; are met. As we will argue later, this is a necessary, but not a sufficient precondition, for learning to take place. The information must also be delivered locally in a manner so its importance is recognized and it must be acted upon. 


\section{Case 3-Fatal accident at CORINA, 2015}

\subsection{CORINA}

M/V CORINA (IMO 8908545) was a general cargo vessel with capacity to carry containers enabling it to carry a variety of bulk and general cargo, length $115 \mathrm{~m}$, gross tonnage 5796 . The vessel was built in 1990 and classed by Germanischer Lloyd. At the time of the accident, the vessel had a crew of eleven, all of Polish nationality. The flag state was Poland.

\subsection{Sources}

Information on this accident is based on a report from the Polish State Maritime Accident Investigation Commission [16], and records from the Danish police [17] and the Danish Working Environment Authority [18], both obtained through the Freedom of Information Act.

\subsection{The accident}

Between 11 April and 20 April 2015, CORINA loaded $6744 \mathrm{t}$ of wood pellets in the Port of Arkhangelsk (Russia). On the 28 April, the vessel arrived at Hanstholm, Denmark, to unload $1921 \mathrm{t}$ before proceeding to The Netherlands.

Company policy required the visible presence of a watchman near the access gangway at all times while at port and an able seaman had the watch from $1600 \mathrm{~h}$. The cook expected him for dinner at about 1700 and eventually informed the chief officer that the able seaman had not shown up. The chief officer searched the ship twice and noticed that the door to the bosun store under forecastle deck was open. Inside, he noticed that the hatch cover to a lashing equipment room at a lower deck in the forepeak was open. He went down and found the seamen there, unconscious. He radioed for help and shortly after, at 1754, the master contacted the port in broken English and requested medical assistance to a heart attack victim.

Within about 15 min a bosun, an electrician and another seaman had come to the accident site to assist and taking turns with cardiac pulmonary resuscitation believing that the unconscious seaman, born in 1947 and overweight at $120 \mathrm{~kg}$, had suffered a heart attack. At about 1810, the port officer arrived at the site with a defibrillator. The port officer soon did not feel well and asked the crew if the air was ok, which was confirmed. After some time one of the crew members, probably the chief officer, attempted to climb the ladder but fell down and received a blow to the head and had to sit down. The first ambulance arrived at 1813 and one of the paramedics soon arrived at the site and began administering oxygen to the able seaman. Six persons were now present in the room. After some time, the paramedic asked the crew if the air was ok, which was confirmed. Shortly after the port officer radioed, the master asking if the air was ok. Only then was the mechanical ventilation switched on. The paramedic ordered everybody out of the room because the air was not ok. Two crew members were unable to climb the ladder and had to be left behind with the unconscious seaman while the other four managed to move up the forepeak and reach the deck, some only with great difficulty. 
Exact times are not available, but the on-scene commander arrived at 1845 at which four ambulances and three vehicles from the emergency services were at the site. A doctor arrived by helicopter at 1855 . Fire fighters donned full respiratory protection extracted the two unconscious crew members who regained consciousness on the deck. At the entry door to the forepeak, CO levels were measured at 66 ppm. Further down 366 ppm were reported. It should be noted that these measurements were taken after mechanical ventilation had been switched on. The able seaman was difficult to extract through the narrow hatch because of his heavy build. He was declared dead at 1940. An autopsy confirmed CO poisoning with COHb measured at $60 \%$. Four crew members and the port officer were admitted to hospital.

\subsection{The investigation}

CORINA was general cargo multipurpose vessel adapted to transport of containers. Containers must be lashed, and in order to ease the handling and movement of lashing gear, the vessel was designed with a $2100 \mathrm{~mm} \times 1150 \mathrm{~mm}$ opening in the forward bulkhead of cargo hold no. 1. The opening allowed easy access to the neighbouring storage room, where chains, stacking cones and other lashing equipment for containers were kept (Figure 3). When carrying bulk cargo, the opening was closed with planks inserted into guide bars. This barrier was not gas tight and gasses from the cargo hold could therefore travel to the forecastle (Figure 4).

The crew was at pains to explain why the able seaman would enter the lashing equipment room. He had no business down there whatsoever and had not requested permission or informed anybody of his intention to go there. He was supposed to be on watch near the gangway.

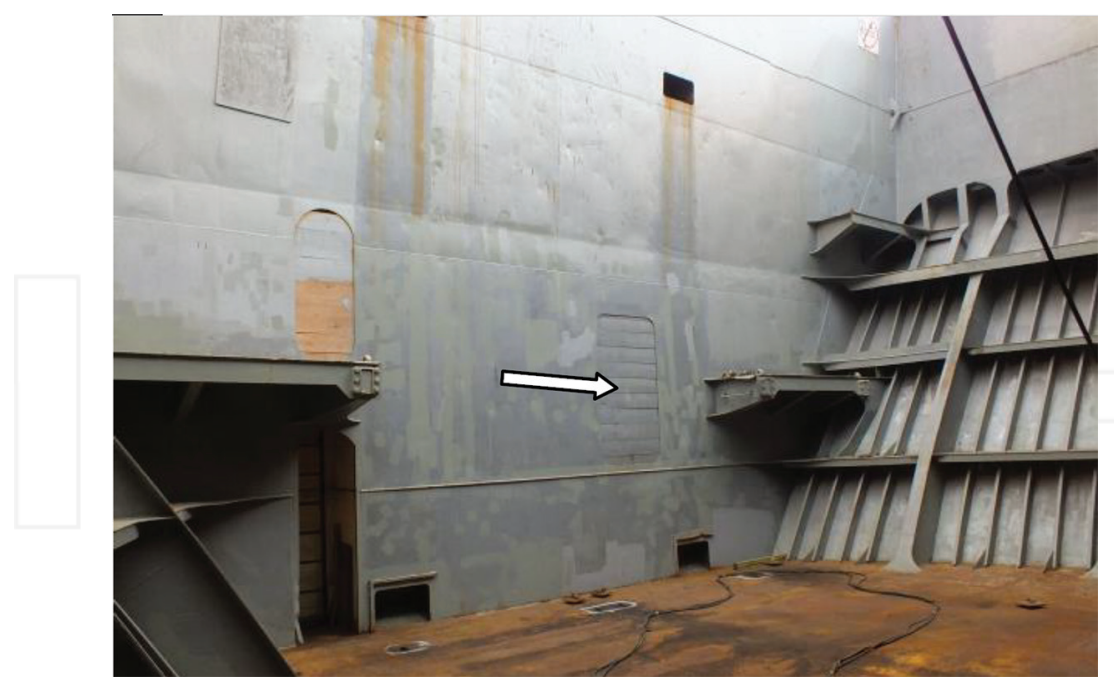

Figure 3. An opening in the front cargo hold allowed easy access to the lashing equipment room. When carrying bulk cargo, the opening was closed with planks of wood inserted into guide bars (CORINA). Source: [16]. 

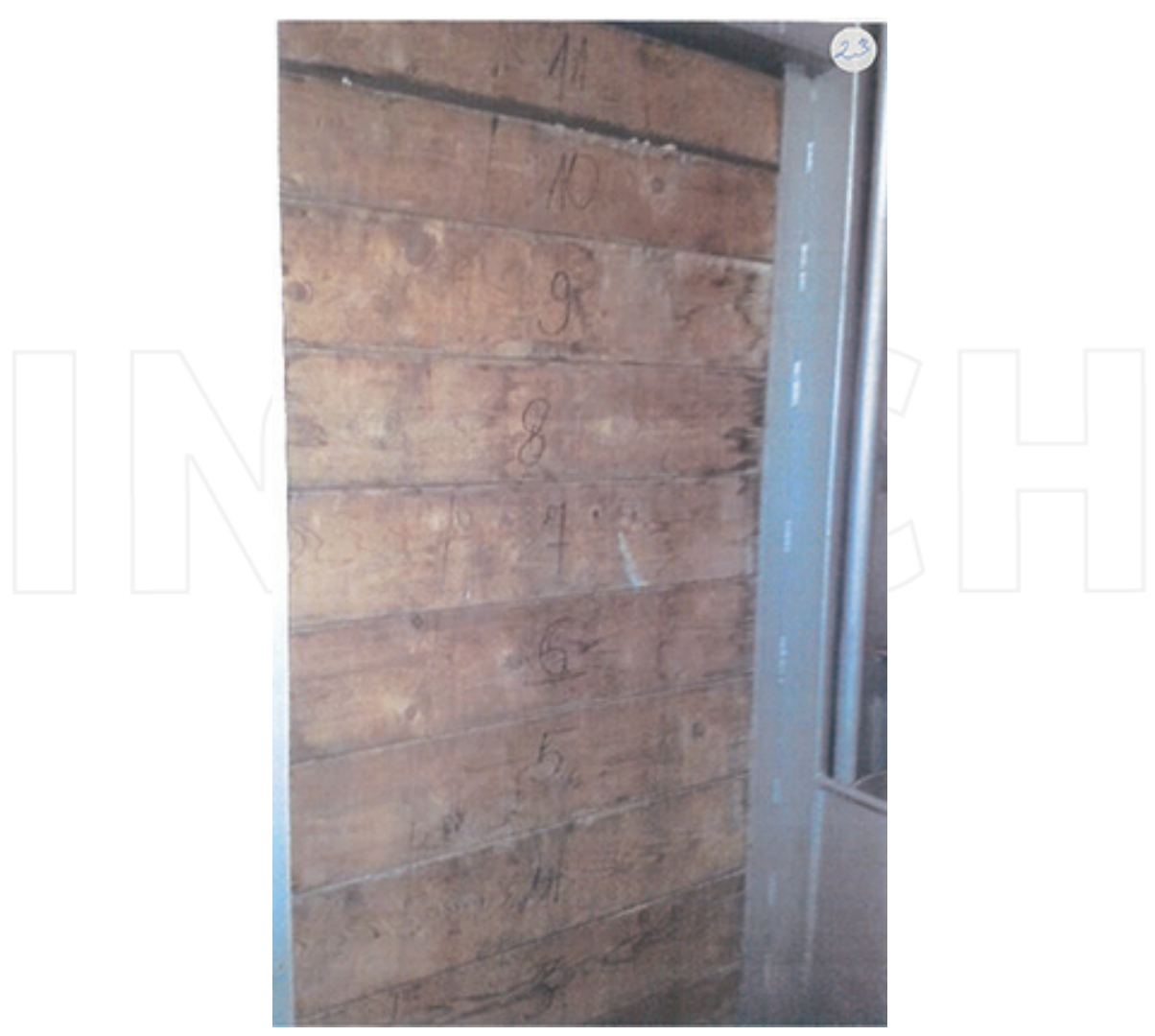

Figure 4. The plank barrier seen from the lashing equipment room. Wood pellets in the cargo hold are visible are visible between planks 10 and 11. The barrier is evidently not gastight. (CORINA). Source: Police photo file \#23 [8].

In line with the International Maritime Solid Bulk Cargoes (IMSBC) Code, the shipper had declared the hazardous nature the cargo. The wood pellets were declared as a group B cargo and marked as Materials Hazardous only in Bulk (MHB), which covers materials that may possess chemical hazards when carried in bulk. The shipper had provided several safety recommendations, only allowing entry to the cargo hold after $2 \mathrm{~h}$ of natural ventilation and measurements of oxygen content and dangerous gasses, carbon monoxide included.

The Polish investigation concluded, however, that crew members likely were unaware of the risks associated with the cargo. Points of entry to hazardous or confined spaces were not marked with warning signs and potential access doors had not been locked to prevent inadvertent entry [16]. To the Danish police, the master explained that he knew that wood pellets could "suck oxygen out of the air" but also that he believed that gasses were present in the cargo hold only, although "he was not a university professor" [17]. 


\subsection{Reflections}

In this recent accident, the hazards associated with wood pellets and preventive measures are clearly stated in the cargo documents. The extent to which this information is fully grasped by the master can be questioned. Seemingly, air quality hazards only became apparent to him after the port officer radioed and asked if the air in the forepeak was ok. Only then did he arrange for the mechanical ventilation to be switched on. Information trickle down from the master to the rest of the crew is obviously doubtful. Again, the actions of the crew demonstrate that they were truly oblivious of the danger. And so were the Danish port officer, the paramedic and probably many more.

Language issues may also have played a role. In particular, the ability of seamen from Eastern Europe with limited proficiency in English to understand hazard codes and guidelines in English, even more so for Russian seamen who may have a preference for information printed in Cyrillic letters.

\subsection{Information sharing and learning?}

The accident was investigated and the findings exhaustively communicated by the Polish State Maritime Accident Investigation Commission [16]. The coverage in Danish media mainly paid attention to the irony that the would-be rescuers succumbed to gasses and themselves became victims but is otherwise riddled with misleading factual errors. For example, the accident is stated to have taken place in the cargo hold because of oxygen depletion, both facts are plain wrong. The source of the hazard, the wood pellets, is correctly identified, however.

\section{Discussion}

\subsection{Accident history involving off-gassing from wood pellets}

Lamentably, strikingly similar serious accidents related to marine transport of solid biomass continue to take place. Publicly available information on these incidents is often scant, however, and as the AMIRANTE case shows, at times incorrect or misleading. The list below (Table 1) has been compiled from various sources and does not claim to be exhaustive. But, it is evident that the release of hazardous gasses from wood pellets in bulk qualifies as an emerging risk for which proper control strategies have yet to be developed.

\subsection{Repetitive patterns in accident aetiology}

The three Danish cases have strikingly similar accident aetiologies:

- the accidents take place in compartments adjacent to the cargo hold

- the compartments are likely covered by IMO's technical definition of an "enclosed room" but the crew does perceive the rooms as being "enclosed"

- dangerous gasses from the cargo hold travel unexpectedly through minor crevices and small gaps unknown to the crew 
- the crew appear oblivious of the hazardous properties of the cargo

- would-be rescuers subject themselves to grave danger

- victims in rooms only accessible using a vertical ladder can only be extracted with great difficulties, in particular if the victim is of heavy build

We are of the opinion that similar accident aetiologies apply to many of the other accidents in the list above though scant publicly available information (and time constraints) prevents a rigorous demonstration of this claim.

\begin{tabular}{|c|c|c|c|c|}
\hline Year & Vessel name, location, accident & Fatal & Injured & Source \\
\hline 2002 & $\begin{array}{l}\text { VEAWER ARROW, Rotterdam (NL), entry into cargo } \\
\text { hold with wood pellets }\end{array}$ & 1 & & {$[10]$} \\
\hline 2005 & EKEN, Gruvön (SE), entry into cargo hold with pulp logs & 1 & & {$[10]$} \\
\hline 2005 & $\begin{array}{l}\text { SAGA FOREST CARRIER, Wilmington (US), working in } \\
\text { open cargo hold with green lumber, oxygen depletion }\end{array}$ & 1 & & {$[16,19]$} \\
\hline 2006 & $\begin{array}{l}\text { SAGA SPRAY, Helsingborg (SE), entry into cargo hold } \\
\text { with wood pellets }\end{array}$ & 1 & Several & [10] \\
\hline 2006 & $\begin{array}{l}\text { NOREN, Skelleftehamn (SE), entry into cargo hold with } \\
\text { wood chips }\end{array}$ & 1 & & {$[10]$} \\
\hline 2007 & FEMBRIA, Timrå (SE), entry into cargo hold with timber & 2 & & {$[10]$} \\
\hline 2009 & $\begin{array}{l}\text { AMIRANTE, Bornholm (DK), entry intro room adjacent } \\
\text { to the cargo hold with wood pellets }\end{array}$ & 2 & 0 & [8] \\
\hline 2010 & $\begin{array}{l}\text { TPC WELLINGTON, New Zealand, entry into cargo hold } \\
\text { with timber }\end{array}$ & 2 & & {$[20]$} \\
\hline 2014 & $\begin{array}{l}\text { LADY IRINA, Fredericia (DK), entry intro room adjacent } \\
\text { to the cargo hold with wood pellets }\end{array}$ & 1 & 3 & [13] \\
\hline 2015 & $\begin{array}{l}\text { CORINA, Hanstholm (DK), entry intro room adjacent to } \\
\text { the cargo hold with wood pellets }\end{array}$ & 1 & 5 & {$[17,16]$} \\
\hline
\end{tabular}

Table 1. Serious accidents related to marine transport of solid biomass known to the authors.

\subsection{The IMO concept of a "confined room" and local sense-making}

The Danish accidents illustrate how the explanatory framework for unsafe atmosphere accidents is based on a discourse that certain rooms are considered confined or enclosed. By implication, the hazard is perceived as being a property of the compartment and not a property of the atmosphere itself or the cargo.

This is particularly evident in the recently revised industry recommendations for entering enclosed spaced aboard ships issued by IMO [21]. The resolution's overall definition of an enclosed space is so broad that it can potentially apply to any space on the ship. However, the examples provided of enclosed spaces are characterized by being spaces that are not part of the normal workspace of the seaman, e.g. fuel tanks, ballast tanks, cargo pump rooms (used on e.g. chemical tankers), etc. 
In the Danish cases, the accidents took place in spaces that were part of the normal working areas of the ship and were routinely accessed. The doors were kept open for practical purposes or convenience. If such rooms are labelled "enclosed" and warning signs posted, as in the LADY IRINA case, the crew may become desensitized and dulled to what is dangerous, because the warnings signs are inconsistent with daily routine and local sense-making.

\subsection{Mental models of accident causation and stop rules}

An accident investigation is a tremendously challenging task. The identification of accident causes is often subjective and guided by the tool box of the analyst rather than the nature of the accident. We subscribe to the ideas of Jens Rasmussen that there is a tendency to see what you expect to find [22], and his proposition [23] that this is a simple reflection of the nature of causal analysis and the fact that no objective "stop rule" exists to terminate the causal back tracking in search of a root cause.

In the AMIRANTE case, the stop rule was from what Jens Rasmussen has termed the "prosecutor's perspective" - the investigation was closed when it was not possible to find somebody to punish. In the LADY IRINA case, the stop rule was from the "therapist's perspective" - the search for causes stopped when a cure known to the analyst was identified (a new procedure and larger warning signs with more text).

The CORINA case was a hybrid, the search stopped when violations were identified (no warning signs and insufficient crew safety instructions) which conveniently also pointed to the cure: improve work procedures and safety training. The accident investigation outcomes above align well with the constructivist thinking of Donald Schön, that the moment we name the things to which we will attend we also frame the context in which we will attend to them [24].

We are of the opinion that it is important to be cognizant of such stop rules. In particular, we note that enhanced proceduralization of work may have limited impact on actual workplace safety. The use of administrative risk controls like procedures may from a managerial perspective be perceived as a time- and cost-effective tool to manage risk, but the actual impact on daily safety can be greatly limited when crew members face multiple and sometimes conflicting goals in their everyday work.

\subsection{The coaster segment-a challenge to reach}

Wood pellets are imported to Denmark on two types of ships: Small tonnage coastal ships (coasters) able to navigate in the shallow and narrow Danish waters calling smaller commercial ports, and larger bulk carriers used for transporting larger quantities to larger ports.

Contrary to coal, wood pellets do not tolerate moisture and cannot be stored in outdoor piles. Wood pellets must be handled under roof or in silos and storage capacity comes at a price. Former coal-fired power plants therefore often face storage capacity limitations. Wood pellets' energy content per unit volume is anywhere from half to one-third of that of coal, which 
furthermore aggravates storage capacity limitations [3]. The limitations call for frequent arrivals of relatively small cargo sizes, a market well-suited for the small coaster segment.

The coasters are usually general cargo ships, i.e. they are designed to carry many different kinds of cargo, e.g. goods on pallets, machinery and various bulk cargoes such as grain, coal and pellets. The high variability of the type of cargo sets limits to the degree of specialization and cargo domain safety knowledge that can be achieved in the small coaster segment.

In addition, coastal ships have, as most ships in international trade, crews of mixed nationality with varying background in training and experience, often from low-wage countries, and sometimes from Russia accustomed to the Cyrillic alphabet. We argue that cargo documents and safety recommendations in English may not be readily absorbed by this group and the work culture may have an oral rather than a written tradition.

\subsection{Media shifting - a sub-optimality}

Environmental interventions may be undertaken with insufficient attention paid to the environment of the workers. The concept of "media shifting" refers to a suboptimal situation which occurs if the "resolution" of a problem within the environmental domain gives rise to new, and unforeseen, problems within other domains, specifically the workplace safety domain [25].

Examples of insufficient attention to workplace safety are sometimes apparent in green reporting and environmental statements, if they omit or misrepresent sections covering occupational health and safety. For example, a study examined "Green Statements" of a biomass pellet facility certified to ISO 14001 and OHSAS 18001-a type of reporting which aims to demonstrate commitments towards sustainability performance. Fire station turnout statistics showed that fires at the facility were frequent. In the sustainability reporting, however, fire and explosion risks were only ranked 11 out of 14, long after more benign, if not trivial issues such as bad acoustics, psychosocial issues and indoor environment problems such as drafts, cold spots and radiant heat [3].

In recent years, critical studies that examine the general topic of balancing safety with sustainability have begun to emerge, see, e.g. $[12,26]$.

Denmark's climate change policy is very ambitious and comprises the conversion of coal-fired thermal power plants to solid biomass fuel in order to reduce carbon dioxide emissions [3]. This chapter points to evidence of media shifting of this climate change intervention that the transport of unprecedented quantities of wood pellets has created new workplace hazards in the marine transportation sector. We argue that the release of hazardous gasses from wood pellets in bulk present as an emerging risk for which proper control strategies have yet to be developed.

The domestic production of wood pellets in Denmark is limited (Figure 5), and more than 95\% are imported and arrive by ship (Table 2). For the period 2001-2015, both years included, we have estimated the domestic production, imports and total consumption 2015 using simple linear inter-/extrapolation, all quantities in SI ton ( $t$ ). For the same period, we have knowledge of three serious accidents on board marine vessel during the import voyage, which resulted in 
four fatalities and eight persons hospitalized after having been exposed to grave danger. For the domestic production, we have knowledge of one fatal accident and five persons hospitalized (at least) after having been exposed to grave danger due to fire and explosion, details cannot be disclosed, however, because of confidentiality agreements.

\section{Wood pellets $(\mathrm{t})$ Denmark, 2001-2014}

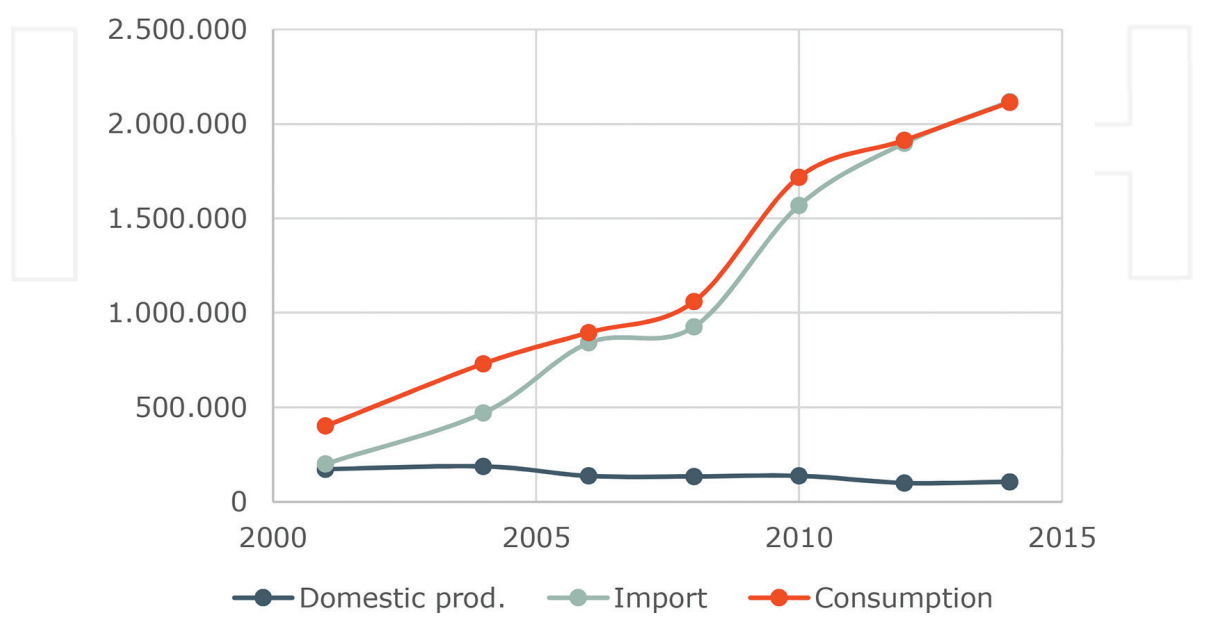

Figure 5. The consumption of wood pellets in Denmark has risen dramatically over the last 15 years.

\begin{tabular}{llll}
\hline Year & Domestic & Import & Consumption \\
\hline 2001 & 173,073 & 200,871 & 401,291 \\
2004 & 187,458 & 470,588 & 731,134 \\
2006 & 137,080 & 841,132 & 895,796 \\
2008 & 134,280 & 925,401 & $1,059,519$ \\
2010 & 137,622 & $1,568,952$ & $1,718,976$ \\
2012 & 99,930 & $1,898,143$ & $1,914,048$ \\
2014 & 106,000 & $2,118,750$ & $2,113,908$ \\
$2001-2015$ (est.) & $2,100,650$ & $17,452,647$ & $19,191,795$ \\
\hline
\end{tabular}

Numbers do not sum due to stockpile changes and (small) exports (Data source: [27]). We estimate the total quantities (t) for 2001-2015.

Table 2. Danish domestic production, imports and consumption (t) of wood pellets for select years 2001-2014.

The numbers allow a crude estimation of the accident rate for imports and domestic production of wood pellets (Table 3). The numbers are not comparable because the import figure 
only comprises accidents (known to us) during the final leg of the marine voyage-excluding for example accidents during biomass harvest, land transport, wood pellet production in the country of origin and loading at the export port.

\begin{tabular}{lll}
\hline & Accident rate per Mt wood pellets \\
\hline & Fatal & Grave danger \\
\hline Produced domestically & 0.48 & 2.38 \\
During marine voyage (import) & 0.23 & 0.46 \\
\hline
\end{tabular}

Table 3. The accident rate per million $t$ wood pellets for accidents with fatal outcome and accidents where an individual is in grave danger, for wood pellets produced domestically and imports (final leg of marine voyage only).

\section{Conclusion}

Common sense tells us that having paid the hefty price of a serious accident, we should use every opportunity to learn from it and prevent recurrence. In the case of the fatal accident on AMIRANTE in 2009, such opportunities were wholly missed. The accident was investigated as a criminal case and the legal system is so designed that findings are kept confidential and out of reach of safety professionals and the general public. This approach has been criticized at an earlier occasion as being entirely misplaced in an accident prevention context [4]. It is a systemic deficiency by design - the bureaucratic judiciary system did not malfunction, it worked precisely as intended. The flag state, St. Vincent \& The Grenadines, did not investigate. As a direct consequence, there was no learning.

Predictably, the accident recurred, at first not in Denmark, but elsewhere. In fact, it would turn out that similar accidents had happened before the AMIRANTE, but lessons learned had not been effectively shared and the crew at AMIRANTE were ignorant of the dangers of wood pellets in bulk.

After AMIRANTE, evidence slowly began to accumulate that wood pellets in bulk present chemical off-gassing hazards that qualify as an emerging risk. It is difficult not to mention the early work, foresight and leadership of the Canadian Wood Pellet association in shedding light on this novel issue [28].

By 2015, there is a comprehensive body of the literature describing the off-gassing hazards and the IMO has launched initiatives and revised the guidelines for management of entry into confined spaces. Unfortunately, very serious repeat accidents continue to recur. That implies that accidents can no longer be attributed to lack of knowledge but a failure to disseminate and use the knowledge available

The general cargo coaster segment appears difficult to reach. Because of the wide range of cargoes carried, there is little specialization and little accumulation of specific cargo safety knowledge.

We doubt if the recently revised IMO guidelines for management of entry into enclosed spaces will be effective. The guidelines are broad and their implementation will likely result 
in compartments - that are part of the normal working areas of the crew and routinely accessed-being labelled as potentially confined spaces. The crew may become desensitized and dulled to danger, because the hazard warnings are inconsistent with local sense-making. The accident history supports this prediction - confined space accidents routinely take place in rooms that are not considered confined spaces by the crew.

In addition, coasters generally have crews of mixed nationality, often from low-wage countries, and sometimes from countries accustomed to the Cyrillic alphabet. We are concerned that cargo documents and written safety recommendations in the English language may not be readily absorbed by this group and the work culture may have an oral rather than a written tradition. An entirely new approach must be sought. More research into this issue and into the existing legal and institutional barriers to learning is required.

The situation is special and delicate because the dramatic increase in the consumption of wood pellets arises out of an ambition to do good - to reduce carbon dioxide emissions and prevent climate change and global warming-often at steep costs to society [3]. It is morally problematic, if climate change environmental interventions are pursued so narrow-mindedly that sight is lost of the environment of the workers, and if workplace safety issues are starved of resources.

Utmost care should be taken to avoid media shifting - that the resolution of a problem within one domain, the environmental, creates a new problem in another, the workplace safety domain.

\section{Acknowledgements}

This article has been produced as voluntary work Opinions expressed are those of the authors, not their employers or organizations. We are thankful to COWI for covering publication expenses.

\section{Conflicts of interest}

None of the contributing authors have conflicts of interest to declare.

\section{Author details}

Frank Huess Hedlund ${ }^{1,2 *}$ and Øssur Jarleivson Hilduberg ${ }^{3}$

*Address all correspondence to: fhuhe@dtu.dk

1 COWI, Kongens Lyngby, Denmark

2 Technical University of Denmark (DTU/Compute), Kongens Lyngby, Denmark

3 Danish Maritime Accident Investigation Board (DMAIB), Valby, Denmark 


\section{References}

[1] H. Petroski, Success through failure: the paradox of design. Princeton University Press, Princeton, New Jersey, 2006

[2] F. H. Hedlund and H. B. Andersen, "Institutional support of learning from accidents: Some obstacles to getting a useful community-wide database in the EU," in Society of Risk Analysis, SRA Europe, Annual Conference, Ljubljana, Slovenia, 2006.

[3] F. H. Hedlund and J. Astad, "Solid biomass climate change interventions examined in a context of inherent safety, media shifting, and emerging risks.," Human and Ecological Risk Assessment: An International Journal, vol. 21, no. 5, pp. 1410-27, 2015.

[4] F. H. Hedlund, J. Astad and J. Nichols, "Inherent hazards, poor reporting and limited learning in the solid biomass energy sector: a case study of a wheel loader igniting wood dust, leading to fatal explosion at wood pellet manufacturer," Biomass and Bioenergy, vol. 66, pp. 450-459, 2014.

[5] G. Thek, I. Obernberger. Pellet handbook: the production and thermal utilisation of biomass pellets. Taylor and Francis, Florence, ISBN: 9781849775328

[6] L. Soto-Garcia, X. Huang, D. Thimmaiah, A. Rossner and P. K. Hopke, "Exposures to carbon monoxide from off-gassing of bulk stored wood pellets," Energy \& Fuels, vol. 29, no. 1, pp. 218-26, 2014.

[7] F. Meier, I. Sedlmayer, W. Emhofer, E. Wopienka, C. Schmidl, W. Haslinger and H. Hofbauer, "Influence of oxygen availability on off-gassing rates of emissions from stored wood pellets," Energy \& Fuels, vol. 30, no. 2, pp. 1006-12, 2016.

[8] "Aktindsigt - afsluttet straffesag vedr. arbejdsulykke på skibet Amirante. Journr. 220010170-00040-15 Bornholms Politi, Rønne. 2015 (Request for information through the Access to Public Administration Files Act)".

[9] S. Gauthier, H. Grass, M. Lory, T. Krämer, M. Thali and C. Bartsch, "Lethal carbon monoxide poisoning in wood pellet storerooms - two cases and a review of the literature," Annals of Occupational Hygiene, vol. 56, no. 7, pp. 755-63, 2012.

[10] U. Svedberg and A. Knutsson, "Hazards and health risk with storage and transport of wood pellets, wood shavings and timber in enclosed spaces. Kunskapsöversikt. Rapport 2011:2 (in Swedish)," Arbets-och miljömedicinska kliniken, Sundsvalls Sjukhus, Sundsvall, Sweden, 2011.

[11] W. Stelte, “Guideline: storage and handling of wood pellets. Resultat Kontrakt (RK) report," Danish technological institute, Energy and climate, Centre for renewable energy and transport, section for biomass, Taastrup, Denmark, 2012.

[12] B. K. Sovacool, R. Andersen, S. Sorensen, K. Sorensen, V. Tienda, A. Vainorius, O. M. Schirach and F. Bjørn-Thygesen, "Balancing safety with sustainability: assessing the risk 
of accidents for modern low-carbon energy systems," Journal of Cleaner Production, vol. 112, pp. 3952-65, 2016.

[13] Carbon monoxide in bow thruster room," Dutch Safety Board (www.safetyboard.nl), The Hague, The Netherlands, 2015.

[14] "Mystery on ship at Fredericia: One dead and four admitted to hospital by invisible killer," BT, 294 2015. [Online]. Available: http://www.bt.dk/danmark/stor-mystik-paaskib-vedfredericia-en-omkom-og-fire-blev-indlagt-af-usynlig-draeb [Accessed 294 2015]

[15] “Officer killed by cargo's fumes”. Telegraph, vol. 48, no. 12), p. 12, Dec 2015 (Published by Nautilus International, London).

[16] "Very serious marine casualty. M/V Corina. Death of seaman and carbon monoxide poisoning of four other persons during port call in Hanstholm on 28 April 2015. Final report-WIM 13/1.5," Polish State Maritime Accident Investigation Commission, Warsaw, Poland, 2016.

[17] "Aktindsigt vedrørende ulykke på skibet Corina i Hanstholm, journr 4100-10170-0054116, Midt- og Vestjyllands Politi, Holstebro, 2016. (Request for information through the Access to Public Administration Files Act).".

[18] "Aktindsigt - dødsulykke på skib, Corina, Hanstholm Havn. Sag 20160049016/2. Tilsynscenter Nord, Arbejdstilsynet, København, 2016. (Request for information through the Access to Public Administration Files Act)".

[19] S. Melin, "Research on off-gassing" and self-heating in wood pellets during bulk storage. Report prepared for Ethanol BC," Wood Pellet Association of Canada, 2011.

[20] J. Koppejan, A. Lönnermark, H. Persson, I. Larsson, P. Blomqvist, M. Arshadi, E. ValenciaReyes, S. Melin, P. Howes, P. Wheeler and D. Baxter, “Health and safety aspects of solid biomass storage, transportation and feeding," IEA Bioenergy, 2013.

[21] "IMO Revised Recommendations for Entering Enclosed Spaces Aboard Ships. IMO Resolution A.1050(27).," The International Maritime Organization (IMO), 2012.

[22] J. Rasmussen, A. M. Pejtersen and L. P. Goodstein, Cognitive Systems Engineering, New York, USA: Wiley, 1994.

[23] J. Rasmussen, P. Nixon and F. Warner, "Human error and the problem of causality in analysis of accidents," Philosophical Transactions of the Royal Society, Series B: Biological Sciences., vol. 327, no. 1241, pp. 449-62, 1990.

[24] D. A. Schön, The Reflective Practitioner: How Professionals Think in Action, Aldershot, England: Arena, 1995 edition.

[25] N. A. Ashford, "Industrial safety: the neglected issue in industrial ecology," Journal of Cleaner Production, 5(1), 115-121., vol. 5, no. 1, pp. 115-21, 1997. 
[26] S. S. Rivera, R. D. C. Olivares, P. A. Baziuk and J. E. N. McLeod, "Assessment of Biofuel Accident Risk: A Preliminary Study," in Proceedings of the World Congress on Engineering, London, U.K., July 1-3, 2015.

[27] M. T. Hansen, “The Danish market for wood pellets 2014 (Tasknummer: 115-25037)," FORCE Technology for Energistyrelsen, Kongens Lyngby, Danmark, 2016

[28] S. Melin, U. Svedberg and J. Samuelsson, "Emissions from wood pellets during ocean transportation (EWDOT). Research report.," Wood Pellet Association of Canada (lead), 2008.
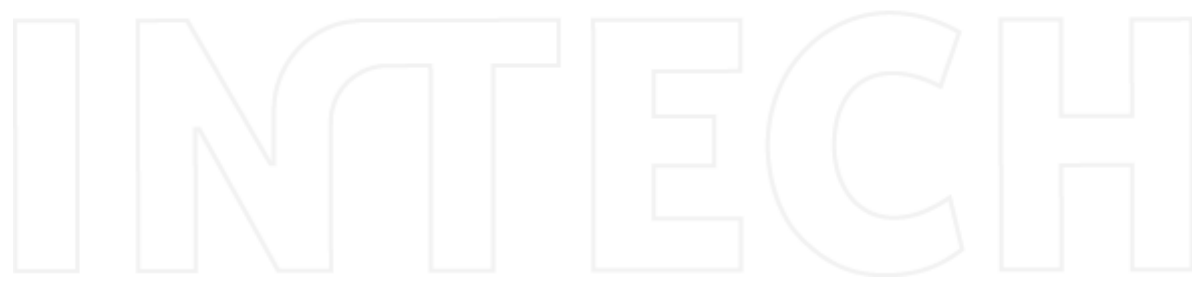

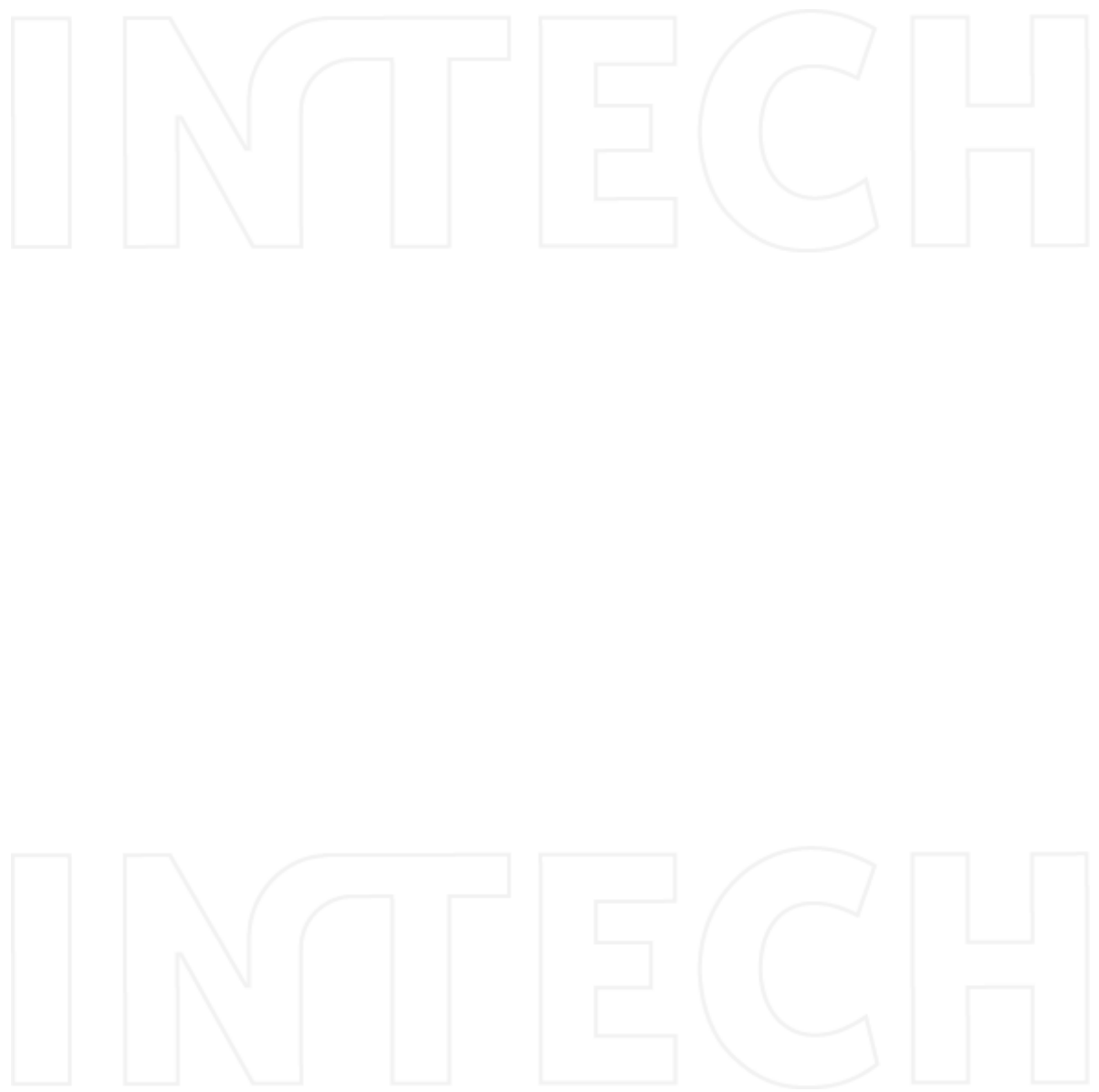